\title{
Online reviews: differences by submission device
}

\section{Article}

\section{Accepted Version}

Creative Commons: Attribution-Noncommercial-No Derivative Works 4.0

Mariani, M. M., Borghi, M. ORCID: https://orcid.org/00000002-4150-1595 and Gretzel, U. (2019) Online reviews: differences by submission device. Tourism Management, 70 . pp. 295-298. ISSN 0261-5177 doi:

https://doi.org/10.1016/j.tourman.2018.08.022 Available at https://centaur.reading.ac.uk/79116/

It is advisable to refer to the publisher's version if you intend to cite from the work. See Guidance on citing.

To link to this article DOI: http://dx.doi.org/10.1016/j.tourman.2018.08.022

Publisher: Elsevier

All outputs in CentAUR are protected by Intellectual Property Rights law, including copyright law. Copyright and IPR is retained by the creators or other copyright holders. Terms and conditions for use of this material are defined in the End User Agreement.

\section{www.reading.ac.uk/centaur}

\section{CentAUR}

Central Archive at the University of Reading 
Reading's research outputs online 


\title{
Online Reviews: Differences by Submission Device
}

Marcello Mariani, Henley Business School, University of Reading Matteo Borghi, Henley Business School, University of Reading

Ulrike Gretzel, Annenberg School for Communication and Journalism, University of Southern California

\begin{abstract}
This study examines the role played by submission devices (mobile vs. desktop) in online travel reviewing behaviour. We analyse over 1.2 million online reviews from Booking.com and detect the presence and distinctive features of online reviews submitted by mobile devices. Our findings indicate that 1) the share of online reviews submitted by mobile increased at a very high rate over time (higher than the growth rate of those submitted by desktop); 2) there is a systematic and statistically significant difference between the features and distributions of online reviews submitted through mobile devices vs. online reviews submitted through desktops. We raise awareness of the role played by submission devices in online travel behaviour research and present implications for future research.
\end{abstract}

Key words: Mobile devices, online reviews, eWOM, mobile eWOM, hospitality, big data. 


\section{Introduction}

Tourism and hospitality management scholars increasingly engage with questions related to online reviews (ORs) because of their significant impact on consumer decision-making (Fang et al., 2016) and company performance (Yang et al., 2018). However, these studies fail to differentiate or control their findings for the submission device used by online reviewers. To address this gap, we examine a large sample of online hotel reviews. The purpose of this work is, first, to raise awareness regarding the relevance of the review submission device when interpreting online review-related findings. Second, the results also address the growing need to better understand online reviewing behaviours via mobile devices.

\section{Mobile Online Reviews}

ORs as a form of electronic word-of-mouth (eWOM) have been researched extensively (see Cantallops \& Salvi, 2014; Kwok et al., 2017 for literature reviews). Findings consistently demonstrate their prominence in travellers' decision making (Baka, 2016; Casaló et al., 2015; Mariani et al., 2014). Despite the abundance of studies that leverage ORs to understand the antecedents and consequences of eWOM in tourism and hospitality (e.g., Ayeh, Au \& Law, 2013; Banerjee \& Chua, 2016; Filieri, 2016), none of them have looked in depth at the role played by the device used to submit ORs or actively questioned if and to what extent the specific communication channel used might affect eWOM behaviour and features. This is rather surprising as, from a practical point of view, consumers increasingly access the Internet through their smartphones (comScore, 2017) and, from a theoretical point of view, scholars have argued that mobile ecosystems are characterized by distinctive information capabilities and pervasiveness that affect consumer behaviour (Lurie et al., 2018).

An analysis of extant literature reveals interesting insights on how eWOM is generated and used across channels (mobiles vs. desktop). For instance, Okazaki (2009) finds that mobile users are more active in generating ORs than their desktop counterparts. Lurie et al. (2014) find that mobile WOM is less reflective, more focused on the present, less subject to retrospective biases, more affective, less cognitive, more one-sided, more negative, and less socially oriented than desktop WOM. Moreover, after controlling for observable differences in content, mobile eWOM appears to be less valued by other consumers. Marz et al. (2017) examine how the helpfulness of mobile eWOM differs from desktop eWOM and conclude that there are significant differences in stylespecific characteristics. Interestingly, they also observe that the knowledge of the type of device the reviewer used to write the review influences other consumers' evaluations of the review's 
helpfulness. Despite these important findings, the topic of mobile eWOM is currently missing from the tourism and hospitality literature.

\section{Methodology}

We deploy a data science approach (Gerard et al., 2016; Mariani, Baggio, Fuchs \& Hopken, 2018) to examining the distribution of ORs over time and across channels (mobile vs. desktop). We scraped the entire population of Booking.com ORs for hotels based in London (UK) over a twoyear time frame (January 1, 2015 to December 31, 2016). Booking.com was selected as it embeds the largest number and share of certified hotel reviews worldwide (Revinate, 2017). The data scraping and analysis were carried out using a web crawler developed in Python. We obtained a total of 1,217,002 reviews across 861 hotels.

To compare ORs, we employed both conventional (Welch two samples t-test) and nonparametric (Mann-Whitney-Wilcoxon Test) statistical tests. We employed nonparametric kernel density estimators to test if the sub-distribution of mobile OR ratings was significantly different from that of desktop ORs. Specifically, we used the Tn-statistic proposed by Li et al. (2009) and tests reported in Maasoumi and Racine (2002) to test if the sub-distribution was equal.

\section{Findings}

\subsection{Submission trends}

There is an increasing trend in the number of ORs submitted overall and specifically by mobile (Figure 1). In January 2015 the number of desktop ORs was higher than the number of mobile ORs, but starting from February 2015 the situation is reversed. Over the 2 years considered, the growth rate of desktop ORs is 11.4\%, increasing from 20,467 in January 2015 to 22,810 in December 2016. Mobile ORs increased by $171.3 \%$ (more than 12 times the rate of desktop ORs) from 14,624 in January 2015 to 39,687 in December 2016. 


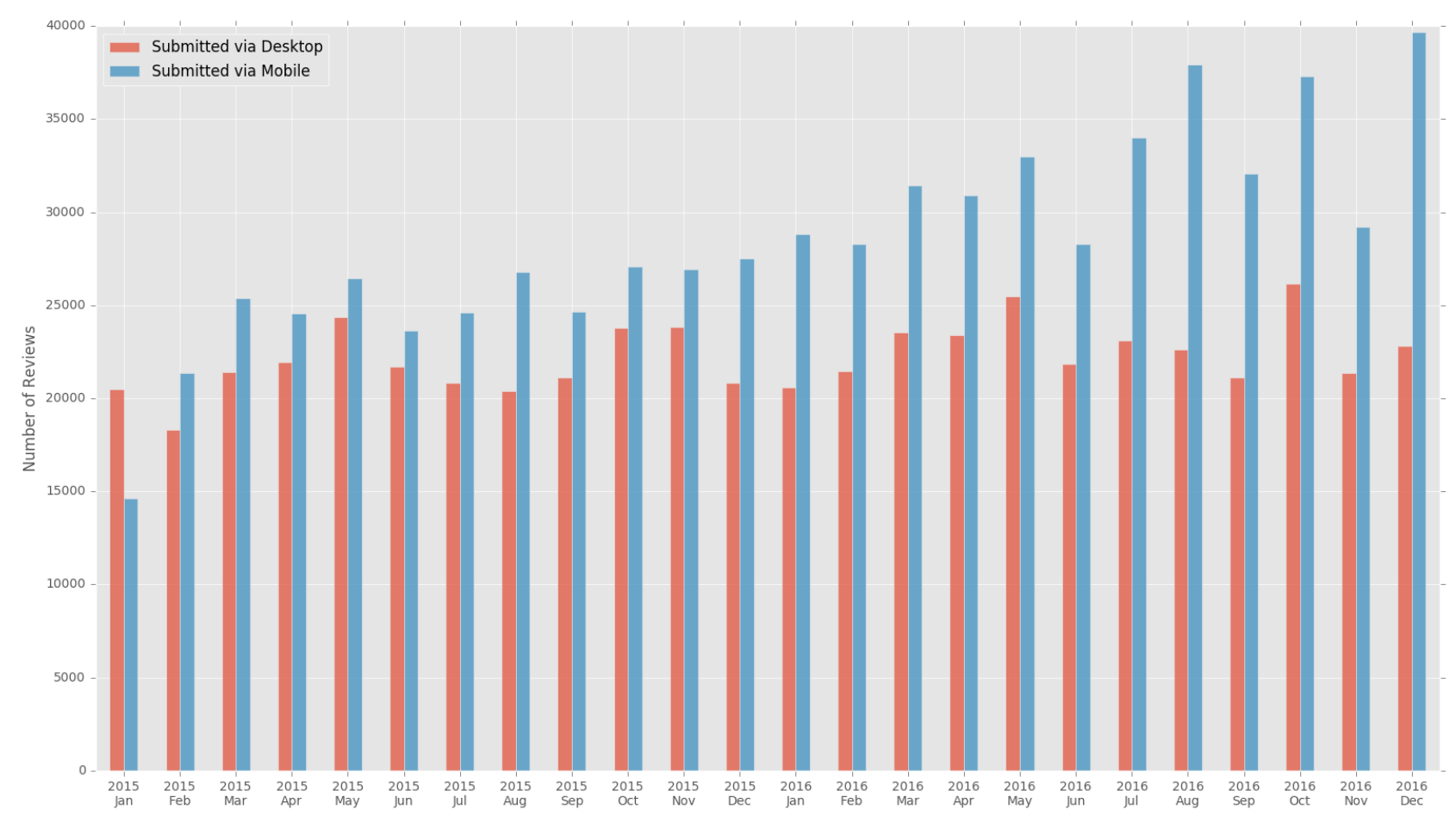

Figure 1. Monthly number of ORs by submission device

\subsection{Differences in mobile vs. desktop ORs}

We created two subsamples: one including all the reviews submitted by desktop $(\mathrm{N}=532,529)$ and the other including the reviews submitted by mobile $(\mathrm{N}=684,473)$. When comparing the subsamples, several statistically significant differences emerged (Table 1).

Table 1 Comparison of means across sub-distributions of ORs by device

\begin{tabular}{|l|c|c|c|c|c|c|c|c|}
\hline & \multicolumn{2}{|c|}{$\begin{array}{l}\text { Total Sample ORs } \\
(\mathrm{N}=1,217,002)\end{array}$} & \multicolumn{2}{c|}{$\begin{array}{c}\text { Mobile ORs } \\
(\mathrm{N}=684,473)\end{array}$} & \multicolumn{2}{c|}{$\begin{array}{c}\text { Desktop ORs } \\
(\mathrm{N}=532,529)\end{array}$} & \\
\hline & Mean & SD & Mean & SD & Mean & SD & t-test & Non parametric test \\
\hline Valence & 7.859 & 1.743 & 7.896 & 1.774 & 7.811 & 1.70 & $\mathrm{t}(1,166,000)=27.023^{* * *}$ & $\mathrm{~W}=174570000000^{* * *}$ \\
\hline $\begin{array}{l}\text { Helpful } \\
\text { Votes }\end{array}$ & 0.201 & 0.677 & 0.182 & 0.638 & 0.224 & 0.723 & $\mathrm{t}(1,067,900)=-33.169^{* * *}$ & $\mathrm{~W}=185890000000^{* * *}$ \\
\hline
\end{tabular}

First, the average rating (valence) for mobile ORs (7.896) is higher than the average rating for desktop ORs (7.811). Mobile ORs are also more polar (the SD for mobile is higher than the SD for desktop). Both distributions are left-skewed. This result is consistent with previous research by Mariani and Borghi (2018). However, the distribution of mobile ORs' ratings (skewness = - 
0.844652 ) is more skewed than the distribution of desktop ORs' ratings (skewness $=-0.775544$ ) as indicated by the nonparametric kernel density estimators (Fig. 2) and the results of the nonparametric tests of equality of the distributions (Li et al., 2009).

Second, the average number of helpful votes for mobile ORs (0.182) is lower than for desktop ORs (0.224). The SD for mobile is lower than for desktop, signalling that even in the most polar cases, mobile ORs are consistently perceived as less helpful than desktop ORs.

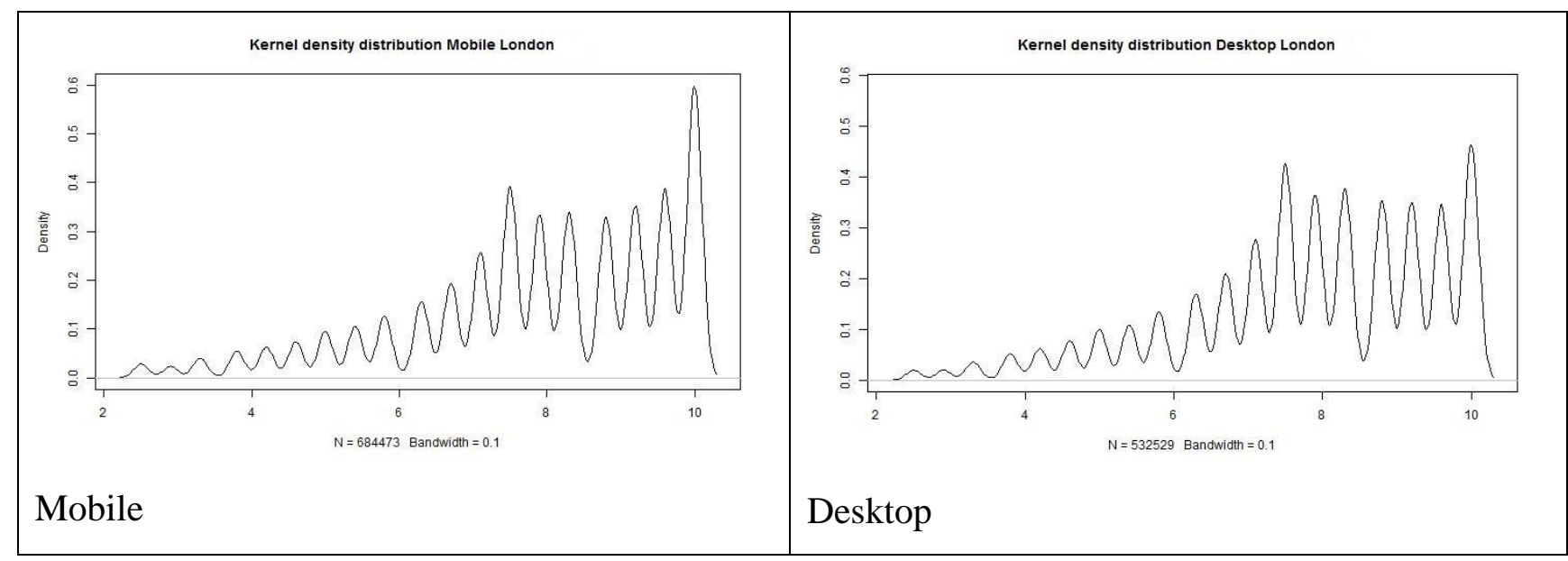

Figure 2. Kernel density distributions

Subsequently, we narrowed the sample to ORs with English texts $(\mathrm{N}=475,462)$ and again divided it into desktop ORs $(\mathrm{N}=201,549)$ and mobile ORs $(\mathrm{N}=273,913)$. The findings show that 1) the average length of the text (in characters) of mobile ORs is lower than of desktop ORs; 2) using the pre-defined split into positive and negative comments provided by Booking.com, we find that both the average length of the positive section and of the negative section are lower for mobile ORs (Table 2).

Table 2 Comparison of means across sub-distributions of OR texts by device

\begin{tabular}{|l|c|c|c|c|c|c|c|c|}
\hline & \multicolumn{2}{|c|}{$\begin{array}{c}\text { Total Sample } \\
(\mathrm{N}=475,462)\end{array}$} & \multicolumn{2}{c|}{$\begin{array}{c}\text { Mobile Reviews } \\
(\mathrm{N}=273,913)\end{array}$} & \multicolumn{2}{c|}{$\begin{array}{c}\text { Desktop reviews } \\
(\mathrm{N}=201,549)\end{array}$} & \\
\hline & Mean & SD & Mean & SD & Mean & SD & t-test & Non parametric test \\
\hline $\begin{array}{l}\text { Review Text } \\
\text { Length (in } \\
\text { characters) }\end{array}$ & 181.636 & 189.770 & 164.475 & 170.735 & 204.957 & 210.702 & $\mathrm{t}(378,360)=-70.826^{* * *}$ & $\mathrm{~W}=31328000000^{* * *}$ \\
\hline Positive Text & 84.549 & 101.886 & 77.0549 & 92.876 & 94.734 & 112.186 & $\mathrm{t}(384,200)=-57.682^{* * *}$ & $\mathrm{~W}=30577000000^{* * *}$ \\
\hline
\end{tabular}




\begin{tabular}{|l|l|l|l|l|l|l|l|l|}
\hline $\begin{array}{l}\text { Length (in } \\
\text { characters) }\end{array}$ & & & & & & & & \\
\hline $\begin{array}{l}\text { Negative } \\
\begin{array}{l}\text { Text Length } \\
\text { (in } \\
\text { characters) }\end{array}\end{array}$ & 97.086 & 150.356 & 87.420 & 136.773 & 110.223 & 166.156 & $\mathrm{t}(382,640)=-50.329 * * *$ & $\mathrm{~W}=29938000000 * * *$ \\
\hline
\end{tabular}

\section{Conclusions and implications}

First, this study reports that 1) the share of mobile ORs is increasing dramatically over time; and, 2) there are systematic and statistically significant differences between the features and distributions of mobile vs. desktop ORs. Consequently, scholars dealing with eWOM today are urged to take this phenomenon into account and to explicitly control for mobile device in their analysis.

Second, our findings suggest that mobile eWOM is considered less helpful than desktop eWOM in line with previous literature (Lurie et al., 2014; Marz et al., 2017). However, in contrast to these existing studies, we find that the valence of mobile eWOM is consistently higher than the valence of desktop eWOM, potentially due to our sample being more recent and larger.

Third, our research exposes important nuances in reviewing behaviours in terms of polarity and length of reviews. This indicates a great need for understanding eWOM behaviour specifically in light of the devices used to submit it. Differences in helpfulness perceptions also call for more research, particularly regarding the extent to which they are caused by mobile OR labels displayed by the review platforms versus review characteristics.

Further, the research also has practical implications. As far as review platforms are concerned, there is a clear need to encourage more elaborate submissions by mobile reviewers. Additionally, mobile ORs might require different response strategies.

This research is not without limitations. Our findings pertain to the population of Booking ORs of hotels located in a specific destination. However, differences could be destination-specific, product-specific and platform-specific. Consequently, additional empirical research is needed to test if the findings can be generalised to other destinations/countries and other types of products (e.g. restaurants or attractions) and hold for other platforms. Furthermore, we focused on a small number of features that could be quantitatively measured. In the future it could be useful to measure other features, such as readability or sentiment polarity. It would also be interesting to understand if the differences detected vary across demographics, different lengths of stay at the hotel, and country of origin of the reviewer and language used for reviewing. Last, our findings are not able to discern 
whether the differences are due to the impact of the submission device or because mobile ORs are submitted by a different segment of reviewers. This should be tested in future research. 


\section{References}

Ayeh, J. K., Au, N. and Law, R. (2013). Predicting the intention to use consumer-generated media for travel planning, Tourism Management, 35, 132-143.

Baka, V. (2016). The becoming of user-generated reviews: Looking at the past to understand the future of managing reputation in the travel sector. Tourism Management, 53, 148-162.

Banerjee, S., \& Chua, A. Y. (2016). In search of patterns among travellers' hotel ratings in TripAdvisor. Tourism Management, 53, 125-131.

Cantallops, A. S., \& Salvi, F. (2014). New consumer behavior: A review of research on eWOM and hotels. International Journal of Hospitality Management, 36, 41-51.

Casalo, L. V., Flavian, C., Guinaliu, M., \& Ekinci, Y. (2015). Do online hotel rating schemes influence booking behaviors?. International Journal of Hospitality Management, 49, 28-36.

comScore (2017). Global Mobile Report. Retrieved from https://www.comscore.com/Insights/Presentations-and-Whitepapers/2017/The-Global-MobileReport, Accessed 27.5.2018.

Fang, B., Ye, Q., Kucukusta, D., \& Law, R. (2016). Analysis of the perceived value of online tourism reviews: Influence of readability and reviewer characteristics. Tourism Management, 52, 498-506.

Filieri, R. (2016). What makes an online consumer review trustworthy? Annals of Tourism Research, 58, 46-64.

Gerard, G., Osinga, E.C., Lavie, D., and Scott, B.A. (2016). Big data and data science methods for management research, Academy of Management Journal, 59(5), 1493-1507.

Kwok, L., Xie, K. L., \& Richards, T. (2017). Thematic framework of online review research: A systematic analysis of contemporary literature on seven major hospitality and tourism journals. International Journal of Contemporary Hospitality Management, 29, 307-354.

Lurie, N. H., Berger, J., Chen, Z., Li, B., Liu, H., Mason, C. H., ... \& Sun, B. (2018). Everywhere and at All Times: Mobility, Consumer Decision-Making, and Choice. Customer Needs and Solutions, 5(1-2), 15-27.

Lurie, N. H., Ransbotham, S., \& Liu, H. (2014). The characteristics and perceived value of mobile word of mouth (Marketing Science Institute Working Paper Series No. 14). Boston: Marketing Science Institute. Retrieved from http://www.msi.org/reports/the-characteristicsandperceived-value-of-mobile-word-of-mouth/.

Maasoumi, E., \& Racine, J. (2002). Entropy and predictability of stock market returns. Journal of Econometrics, 107(1-2), 291-312.

Marz, A. Schubach, S. \& Schumann, J.H. (2017). Why Would I Read a Mobile Review?” Device Compatibility Perceptions and Effects on Perceived Helpfulness. Psychology \& Marketing, 34(2): 119-137.

Mariani, M. M., \& Borghi, M. (2018). Effects of the Booking.com rating system: Bringing hotel class into the picture. Tourism Management, 66, 47-52.

Mariani, M.M., Baggio, R., Fuchs, M., Höpken, W. (2018). Business Intelligence and Big Data in Hospitality and Tourism: A Systematic Literature Review. International Journal of Contemporary Hospitality Management, 30(10), forthcoming.

Mariani, M.M., Baggio, R., Buhalis, D., Longhi, C., 2014, Tourism Management, Marketing and Development, Volume I: the Importance of Networks and ICTs. New York: Palgrave.

Okazaki, S. (2009) Social influence model and electronic word of mouth, International Journal of Advertising, 28(3), 439-472.

Li, Q., Maasoumi, E. \& Racine, J. (2009) A nonparametric test for equality of distributions with mixed categorical and continuous data, Journal of Econometrics, 148 (2), 186-200. 
Revinate (2017). Global Hotel Reputation Benchmark Report 2017, accessed on the 30/5/2018 from https://learn.revinate.com/hospitality-research-studies/global-hotel-reputation-benchmarkreport-2017 .

Yang, Y., Park, S., \& Hu, X. (2018). Electronic word of mouth and hotel performance: a metaanalysis. Tourism Management, 67, 248-260. 